\title{
Total energy expenditure and energy intake in the pre-school child: a comparison
}

\author{
BY PETER S. W. DAVIES AND W. A. COWARD \\ Dunn Nutrition Unit, Downham's Lane, Milton Road, Cambridge CB4 IXJ \\ AND J. GREGORY AND A. WHITE \\ Office of Population Censuses and Surveys, St Catherine's House, 10 Kingsway, London WC2B 6JP \\ AND A. MILLS \\ Ministry of Agriculture Fisheries and Food, Nobel House, 17 Smith Square, London SW1P 3JR
}

(Received 21 April 1993 - Revised 20 October 1993 - Accepted 16 November 1993)

\begin{abstract}
In a cohort $(n 81)$ of healthy children aged 1.5-4.5 years, measurements of energy intake and energy expenditure were compared. Energy intake was calculated following a $4 \mathrm{~d}$ weighed record completed by the mother or guardian of the child. Total energy expenditure was measured using the doubly-labelled water technique. Mean energy intake and expenditure in the cohort were $4773 \mathrm{~kJ} / \mathrm{d}$ and $4928 \mathrm{~kJ} / \mathrm{d}$ respectively. The mean relative bias between the techniques was $154 \mathrm{~kJ} / \mathrm{d}$. In the older children (3.5-4.5 years) the mean relative bias was only $37 \mathrm{~kJ} / \mathrm{d}$. At the population level the measurements of energy intake and energy expenditure were extremely close, and the study has provided sufficient confidence in weighed intake methodology for it to be used in a major nationwide study of dietary intake and nutritional status of children aged $1.5-4.5$ years.
\end{abstract}

Energy intake: Energy expenditure: Childhood

The programme of National Diet and Nutrition Surveys (NDNS) sponsored by the Department of Health and the Ministry of Agriculture Fisheries and Food (MAFF) investigates the diets and nutritional status of representative samples of the British population. The first group in this programme is children aged $1.5-4.5$ years. This paper describes work that was done as a preliminary to the main study. There were major concerns that weighed dietary records in this age group might not give a sufficiently accurate picture of the dietary intake.

Dietary assessment via weighed intake records has formed the basis of numerous studies of nutrition in man. In clinical work it has been recommended that weighed food intake records of up to $14 \mathrm{~d}$ are required while in epidemiological studies at least $3 \mathrm{~d}$ data are needed (Bingham, 1987). This methodology is time consuming and may lead to alterations in the dietary intake of the subject. Moreover, it has been suggested that such studies have a potential bias to under-recording both in normal individuals and in the obese (Southgate, 1986; Livingstone et al. 1990). Bandini et al. (1990) have shown significant underestimation of food intakes assessed by dietary record by both lean and obese adolescents when compared with energy expenditure estimated from the doubly-labelled water technique.

In the absence of data pertaining to total energy expenditure in healthy, normally growing infants and children the Food and Agriculture Organization/World Health Organization/United Nations University (1985) recommendations for daily energy intake are based upon studies of weighed food intake that span the last 50 years. These data show 
a secular trend towards lower intakes in recent years. The level of agreement between measurements of food energy intake via weighed intakes in infants and measurements of total energy expenditure is unknown.

The doubly-labelled water technique allows the non-invasive estimation of total energy expenditure, and is increasingly being used as a basis for comparison with weighed intake data. We have therefore made estimates of total energy expenditure using the doublylabelled water technique and measured energy intake with a $4 \mathrm{~d}$ weighed intake record in children aged $1.5-4.5$ years.

\section{SUBJECTS AND METHODS}

\section{Subjects}

The survey covered children aged between 1.5 and 4.5 years. To compare energy intake and energy expenditure across the whole age range, and for boys and girls separately, quota sampling was used to ensure roughly equal numbers from each sex and from each of the three age groups ( $1.50-2.49$ years, $2.50-3.49$ years, $3.50-4.49$ years).

Children were selected from eight different towns in and around Cambridgeshire (Cambridge, Bury St. Edmunds, Royston, Stevenage, Luton, Huntingdon, Peterborough and Harlow). A number of towns were chosen in order to maximize the opportunity of recruiting families from different socio-economic groups and families with different eating patterns. In each area children were identified by one of three methods: by calling at randomly selected addresses; by calling at an address suggested by someone contacted at one of these addresses; or through a playgroup in the area. Only one child per household was studied; in the cases where there was more than one suitable child in the household, the child to be studied was selected randomly. Ethical approval was obtained from the local area ethical committees. Written, informed parental consent was obtained and the children were told about the procedures.

In all, 202 households were approached, yielding 146 eligible children. Of these, only those agreeing to all elements of the survey were recruited. Ninety-three $(64 \%)$ fully cooperated with all aspects of the survey. The study took place in the autumn of 1989 .

\section{Weighed intake of food and drink}

The mother or guardian of the child was asked to keep a weighed intake record of all food and drink consumed by the child both in and out of the home for a period of four consecutive days which included Saturday and Sunday. This was felt to be a sufficient period over which to catch most of the range of foods that children of this age eat, but not too long to affect adversely the quality of the response. Mothers were provided with Soehnle Digital Weighing Scales and were instructed to weigh each served food item separately and record this in detail. Any leftovers were reweighed; where food was lost or spilt and could not be reweighed estimates of the amount or proportion of the served weight lost were recorded. The mother was given a small notebook in which to record full details of any items that were consumed away from home when weighing was not possible.

The weight of each food item consumed was calculated by subtracting the weight of leftovers from the served weight. An allowance was made for any food spilled or lost. Food items were then converted to their constituent nutrients. Intakes of forty-four nutrients and energy were calculated from the food records using a specially developed nutrient databank. The nutrients assigned to each food came from McCance and Widdowson's The Composition of Foods (Paul \& Southgate, 1978) and its supplements (Tan et al. 1985; 
Holland et al. 1988; Holland et al. 1989), MAFF's ongoing programme of nutritional analyses, manufacturers' data, published scientific literature and, where appropriate, food composition tables from other countries. Data were evaluated and where they were considered still to be valid they were included in the nutrient databank. For homemade dishes and manufactured products for which no other data were available, nutrients were calculated from their constituents using a computer recipe programme. A mean energy intake from the $4 \mathrm{~d}$ was calculated.

\section{Total energy expenditure}

Total energy expenditure was measured using the doubly-labelled water technique. Two stable, non-toxic isotopes $\left({ }^{18} \mathrm{O}\right.$ and $\left.{ }^{2} \mathrm{H}\right)$ were administered as water, orally. A dose consisting of $0 \cdot 125 \mathrm{~g} / \mathrm{kg}$ body weight $\mathrm{H}_{2}{ }^{18} \mathrm{O}$ and $0 \cdot 05 \mathrm{~g} / \mathrm{kg}$ body weight ${ }^{2} \mathrm{H}_{2} \mathrm{O}$ (deuterium oxide) was administered from a standard $100 \mathrm{ml}$ bottle via a drinking straw. In each case the weight of the dose given in grams was determined to four decimal places.

A single urine sample was collected before the administration of the dose to determine natural concentrations of ${ }^{2} \mathrm{H}$ and ${ }^{18} \mathrm{O}$ in body fluids. A timed urine sample was then collected daily for $10 \mathrm{~d}$. The $4 \mathrm{~d}$ weighed intake took place within this $10 \mathrm{~d}$ period. Isotopic enrichment of the urine samples was measured relative to a local standard by isotope ratio mass spectrometry (Aqua-Sira model; VG Isotech, Crewe, Ches.).

Results were expressed as \%o (per mil) enrichment relative to Standard Mean Ocean Water (SMOW). Thus,

$$
\delta \text { enrichment }=\frac{R_{S}}{R_{R}}-1 \times 10^{3},
$$

where $R_{S}$ is the isotope ratio of the sample and $R_{R}$ is the concentration (parts per million) of the isotopes in SMOW $\left({ }^{2} \mathrm{H}=155 \cdot 95,{ }^{18} \mathrm{O}=2005 \cdot 2\right)$.

In this laboratory linear regression equations were obtained from the log transforms of measured enrichments of ${ }^{2} \mathrm{H}$ and ${ }^{18} \mathrm{O}$ against time. The regression coefficients are therefore the disappearance rates $k_{a}$ and $k_{o}$ of ${ }^{2} \mathrm{H}$ and ${ }^{18} \mathrm{O}$ respectively.

The dilution space (g) of each isotope $\left(N_{o}, N_{d}\right)$ at the beginning of the study period is calculated as

$$
N=\frac{T A}{a}\left(\frac{E_{a}-E_{t}}{E_{s}-E_{p}}\right),
$$

where $N_{o}$ is the ${ }^{18} \mathrm{O}$ dilution space, and $N_{d}$ is the deuterium dilution space. $A$ is the dose of isotope $(\mathrm{g})$ given to the child, $a$ is a portion of the dose $(\mathrm{g})$ diluted for mass-spectrometric analysis in a mass $T(\mathrm{~g})$ of tap water. $E_{a}$ is enrichment of the portion, $E_{t}$ is enrichment of tap water, $E_{s}$ is the antilog of the intercept of the regression line and $E_{p}$ is enrichment of pre-dose urine sample.

Output rates of carbon dioxide $\mathrm{rCO}_{2}(\mathrm{~mol} / \mathrm{d})$ corrected for fractionation effects were calculated using a constant value for the proportion of water fractionated $(x)$ and values for the fractionation of ${ }^{2} \mathrm{H}$ and ${ }^{18} \mathrm{O}\left(f_{1}\right.$ and $\left.f_{2}\right)$ in water vapour and ${ }^{18} \mathrm{O}\left(f_{3}\right)$ in $\mathrm{CO}_{2}$.

The value of $x$ used in the present study was 0.25 and the values for $f_{1}, f_{2}$ and $f_{3}$ were $0.941,0.993$ and 1.040 respectively.

$\mathrm{CO}_{2}$ production rate was calculated as,

$$
r C O_{2}=\frac{N_{o} k_{o}-N_{d} k_{d}\left(1+\left(f_{2}-f_{1}\right) x\right)}{2 f_{3}}
$$

Assuming a respiratory quotient of $0 \cdot 85$, total energy expenditure can be calculated using 
Table 1. Energy intake and expenditure in a cohort of eighty-one children, and with the cohort divided into three age categories*

(Mean values and standard deviations)

\begin{tabular}{|c|c|c|c|c|c|}
\hline \multirow[b]{3}{*}{ Age (years) } & \multirow[b]{3}{*}{$n$} & \multicolumn{4}{|c|}{ Energy $(\mathrm{kJ} / \mathrm{d})$} \\
\hline & & \multicolumn{2}{|c|}{ Intake } & \multicolumn{2}{|c|}{ Expenditure } \\
\hline & & Mean & $\mathrm{SD}$ & Mean & SD \\
\hline $1.50 \quad 4.50$ & 81 & 4773 & 838 & 4928 & 987 \\
\hline $\begin{array}{l}1 \cdot 50-2 \cdot 49 \\
2 \cdot 50-3 \cdot 49 \\
3 \cdot 50-4 \cdot 49\end{array}$ & $\begin{array}{l}23 \\
31 \\
27\end{array}$ & $\begin{array}{l}4204 \\
4635 \\
5418\end{array}$ & $\begin{array}{l}631 \\
740 \\
635\end{array}$ & $\begin{array}{l}4472 \\
4874 \\
5380\end{array}$ & $\begin{array}{r}1062 \\
828 \\
916\end{array}$ \\
\hline
\end{tabular}

* For details of subjects and procedures, see pp. 14-16.

Weir's (1949) formula. This represents a mean total energy expenditure over the $10 \mathrm{~d}$ period. Propagation of error analysis for the method was carried out as described by Cole \& Coward (1992).

In individuals in energy balance and with zero growth over a period of days, total energy expenditure will be equal to total energy intake. In the age range of children in this study the energy stored in new tissue, that is growth, will be a very small proportion (approximately $2 \%$ ) of total energy intake.

\section{Statistical methods}

The data were analysed using the Bland \& Altman (1986) technique for assessing agreement between two methods of measurement. This analysis was applied to the entire data set, and to the data divided into three age categories; $1 \cdot 50-2 \cdot 49$ years, $2 \cdot 50-3 \cdot 49$ years, and $3 \cdot 50-4 \cdot 49$ years. The Bland \& Altman (1986) analysis allows any bias between the two measurements to be assessed and the calculation of the limits of agreement between the methods.

\section{RESULTS}

Measurements of energy intake and energy expenditure were successfully achieved for eighty-one children (thirty-nine females, forty-two males). The mean and standard deviation for total energy intake and total energy expenditure for the entire cohort and the three age groups are shown in Table 1. A scatter plot of the mean daily total energy intake $v$. the mean daily total energy expenditure for the entire cohort is shown in Fig. 1. A plot of the mean of the two measurements $v$. their difference is usually more informative when considering bias. Such a plot is shown in Fig. 2. The difference was calculated as energy intake minus energy expenditure. The relative bias is calculated as the mean difference between the two methods with the limits of agreement being defined as the bias \pm two standard deviations of the difference. The bias and limits of agreement for the entire cohort and for the three age groups are shown in Table 2.

The mean standard error of the estimate (SEE) of $\mathrm{CO}_{2}$ production rate was $4 \cdot 1 \%$. The mean SEE of energy intake based upon the $4 \mathrm{~d}$ recording was $10.3 \%$. The correlations and their significance between estimates of energy intake and energy expenditure in $\mathrm{kJ} / \mathrm{d}$ and $\mathrm{kJ} / \mathrm{kg}$ in the cohort are shown in Table 3. 


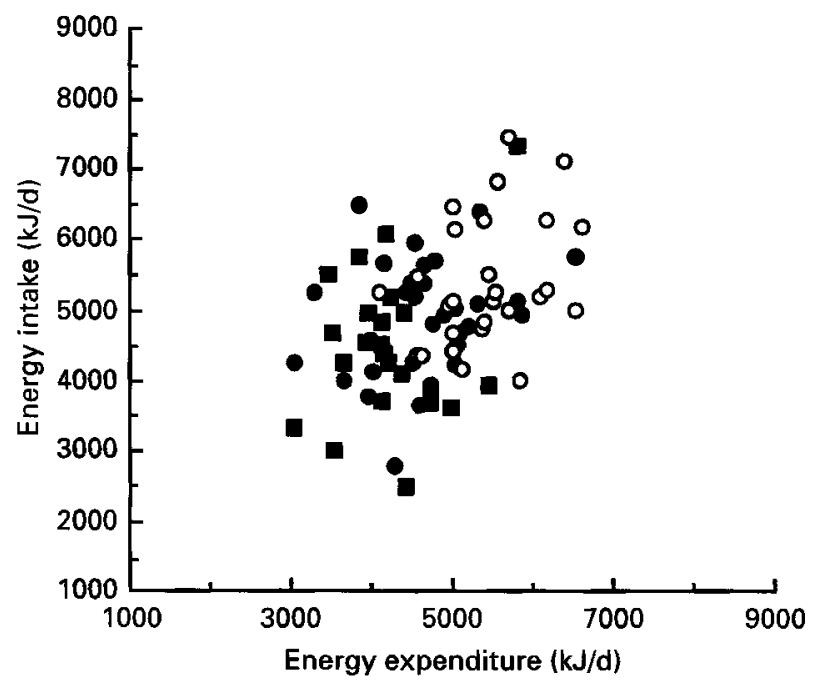

Fig. 1. A scatter plot of total energy expenditure $(\mathrm{kJ} / \mathrm{d})$ and energy intake $(\mathrm{kJ} / \mathrm{d})$ in a cohort of eighty-one children

( $\boldsymbol{\square}$, children aged $1.50-2.49$ years;, $2.50-3.49$ years; $0,3.5-4.5$ years).

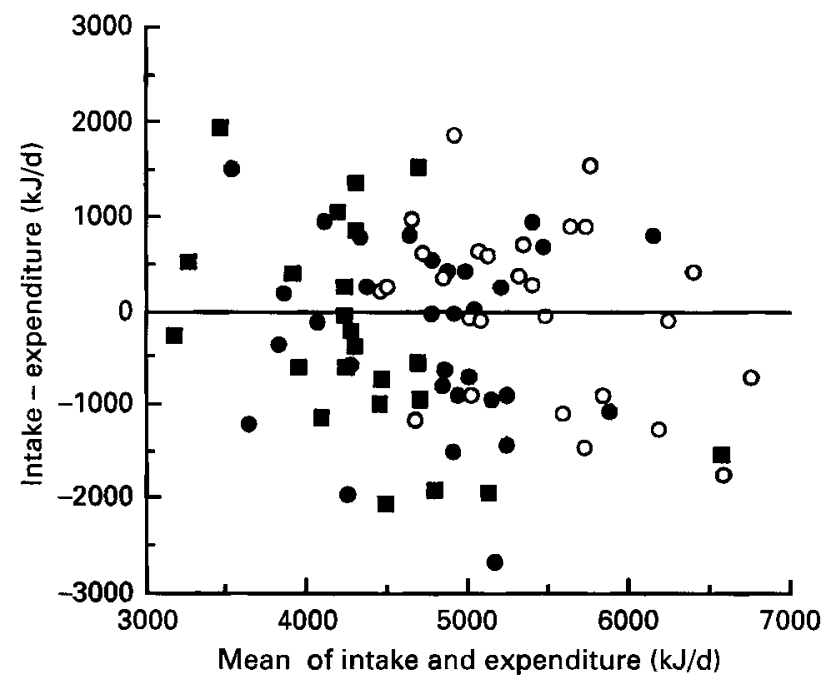

Fig. 2. The difference between the measures of energy intake and energy expenditure $v$. the mean of the two measures ( $\square$, children aged $1 \cdot 50-2 \cdot 49$ years; $0,2 \cdot 50-3 \cdot 49$ years; $0,3 \cdot 5-4 \cdot 5$ years).

\section{DISCUSSION}

For individuals in energy balance over a period of days, energy intake will be equal to energy expenditure. Thus comparison of energy intake and expenditure are valid so long as the energy stored as new tissue, i.e. growth, is not an important or major component of energy intake. In early infancy the percentage of energy laid down in new tissue is very high, of the order of $30 \%$ in the first few weeks of life. However, the energy stored in new tissue diminishes very rapidly and in the age range of the children recruited into this study, the energy cost of growth is about $2 \%$ of intake.

Table 1 shows that the mean intakes and expenditures are similar in both the entire 
Table 2. The relative bias and limits of agreement of the measurements of energy intake and expenditure for a cohort of eighty-one children and with the cohort divided into three age categoriest

\begin{tabular}{cccc}
\hline \hline Age (years) & $n$ & $\begin{array}{c}\text { Relative bias } \\
(\mathrm{kJ})\end{array}$ & $\begin{array}{c}\text { Limits of agreement } \\
(\mathrm{kJ})\end{array}$ \\
\hline $1 \cdot 50-4 \cdot 50$ & 81 & -154 & \pm 1991 \\
$1 \cdot 50-2 \cdot 49$ & 23 & -267 & \pm 2242 \\
$2 \cdot 50-3 \cdot 49$ & 31 & -238 & \pm 1933 \\
$3 \cdot 50-4 \cdot 49$ & 27 & +37 & \pm 1845 \\
\hline \hline
\end{tabular}

$\dagger$ For details of subjects and measurements, see pp. 14-16.

Table 3. Correlation coefficients and their levels of significance between estimates of energy intake and expenditure (expressed as $\mathrm{kJ} / \mathrm{d}$ and $\mathrm{kJ} / \mathrm{kg}$ ) in a cohort of eighty-one children, and with the cohort divided into three age categories $\dagger$

\begin{tabular}{ccc}
\hline \hline & & \multicolumn{2}{c}{$\begin{array}{c}\text { Correlation coefficients for } \\
\text { energy intake } v \text {. expenditure }\end{array}$} \\
\cline { 2 - 3 } Age (years) & $\mathrm{kJ} / \mathrm{d}$ & $\mathrm{kJ} / \mathrm{kg}$ \\
\hline $1 \cdot 5-4 \cdot 5$ & $0.41^{* *}$ & $0.36^{* *}$ \\
$1 \cdot 5-2.49$ & 0.20 & $0.37^{* *}$ \\
$2 \cdot 4-3.49$ & $0.24^{*}$ & $0.33^{* *}$ \\
$3 \cdot 5-4.49$ & $0.34^{* *}$ & $0.37^{* *}$ \\
\hline \hline
\end{tabular}

* $P<0.05 ; * P<0.01$.

$\dagger$ For details of subjects and measurement procedures, see pp. 14-16.

cohort and the individual age groups. A much larger bias of $6.0 \%$ occurs in the $1.5-2.5$ year group of children, whilst for the entire cohort there is a difference of $3.0 \%$. The Bland \& Altman (1986) analysis summarized in Table 2 would indicate that there is a bias for intake to be less than expenditure at most ages. Much larger biases have been reported in equivalent studies on other age groups. Livingstone et al. (1990) reported a $20 \%$ difference between energy intake and expenditure in a group of thirty-one adults. Differences of the order of $20 \%$ have also been found in adolescent boys and girls (Livingstone et al. 1992). In contrast, in highly controlled dietary studies such as those of Goldberg et al. (1991) agreement between intake and expenditure was extremely good.

It is possible that eating habits are altered during weighed intake measurement. However, differences between measurements of energy intake and energy expenditure found in previous studies are thought to be due primarily to under-recording of consumed food. Thus we must consider why the same mechanism does not seem to have such a large influence in the age group studied here. It is usually stated that under-reporting of food intake occurs due to a combination of forgetfulness, deliberate lack of compliance, and guilt concerning eating habits. In the present study, primary control of the $4 \mathrm{~d}$ weighed intake was in the hands of the parents or guardian of the children studied. Thus a relatively high degree of compliance might be expected. Also, children of the ages studied here have much less unsupervised access to supplementary sources of food, i.e. snacks such as crisps and chocolate. Moreover, there is less out-of-home eating, particularly in non-domestic 
settings, by this age group than for other age groups; all these factors make it more likely that intakes will be more accurately recorded.

It is noteworthy that in the oldest group of children aged 3.5-4.49 years the weighed dietary record gave an energy intake greater than the measured expenditure. Similar findings have been reported in slightly older children (Livingstone et al. 1992). This may be a significant bias which would ultimately lead to the potential development of obesity or may reflect random error in the measurement of total energy expenditure and energy intake. The relatively few studies that have compared energy intake and energy expenditure in childhood show that by early adolescence, reported energy intake is lower than measured energy expenditure (Bandini et al. 1990; Livingstone, et al. 1992).

Although the population means for the entire cohort and the different age groups are similar, it will be apparent from Fig. 2 and the limits of agreement shown in Table 2 that there were some very large individual differences between total energy expenditure and energy intake. The SEE of each technique can be calculated. The mean SEE of $\mathrm{CO}_{2}$ production using the doubly-labelled-water technique of $4.1 \%$ is comparable with that found in previous studies. The mean SEE of energy intake of $10.3 \%$ is equivalent to a coefficient of variation of $20.0 \%$. This again is very similar to other estimates in children of similar age (Black et al. 1983; Nelson et al. 1989). Thus one would expect $95 \%$ of the differences between energy intake and energy expenditure to be within $2 \times \sqrt{ }(4 \cdot 1)^{2}+$ $(10 \cdot 3)^{2} \%$ of the mean value, i.e. $\pm 22 \cdot 2 \%$ of the mean value. Thus for the entire cohort one would expect $95 \%$ of the differences to be between $-1066 \mathrm{~kJ}$ and $+1066 \mathrm{~kJ}$. In fact, $76 \%$ of measurements fell within this range.

At the population level the measurements of energy intake and energy expenditure were extremely close. The average difference of only $3 \%$ has provided sufficient confidence in weighed intake methodology for it to be used in a major nationwide study of dietary intake and nutritional status of children aged $1 \cdot 5-4 \cdot 5$ years.

This study was funded jointly by the Ministry of Agriculture Fisheries and Food and the Department of Health and conducted by the Social Survey Division of the Office of Population Censuses and Surveys in conjunction with the Medical Research Council Dunn Nutrition Unit, Cambridge.

\section{REFERENCES}

Bandini, L. G., Schoeller, D. A., Cyr, H. N. \& Dietz, W. H. (1990). Validity of reported energy intake in obese and non-obese adolescents. American Journal of Clinical Nutrition 52, 421-425.

Bingham, S. A. (1987). The dietary assessment of individuals, methods, accuracy, new techniques and recommendations. Nutrition Abstracts and Reviews 57, 705-741.

Black, A. E., Cole, T. J., Wiles, S. J. \& White, F. (1983). Daily variations in food intake of infants from 2-18 months. Human Nutrition: Applied Nutrition 37A, 448-458.

Bland, J. M. \& Altman, D. G. (1986). Statistical methods for assessing agreement between two measures of clinical measurement. Lancet i, 307-310.

Cole, T. J. \& Coward, W. A. (1992). Precision and accuracy of doubly labelled water, energy expenditure by the multi-point and two-point methods. American Journal of Physiology 263, E965-E972.

Food and Agriculture Organization/World Health Organization/United Nations University (1988). Energy and Protein Requirements. World Health Organization Technical Report Series no. 724. Geneva: WHO.

Goldberg, G. R., Prentice, A. M., Coward, W. A., Davies, H. C., Murgatroyd, P. R., Sawyer, M. B., Ashford, J. \& Black, A. E. (1991). Longitudinal assessment of the components of energy balance in well-nourished lactating women. American Journal of Clinical Nutrition 54, 788-798.

Holland, B., Unwin, I. D. \& Buss, D. H. (1988). Cereals and Cereal Products. Third Supplement to McCance and Widdowson's The Composition of Foods. Cambridge: Royal Society of Chemistry.

Holland, B., Unwin, I. D. \& Buss, D. H. (1989). Milk Products and Eggs. Fourth Supplement to McCance and Widdowson's The Composition of Foods. Cambridge: Royal Society of Chemistry.

Livingstone, M. B. E., Prentice, A. M., Coward, W. A., Strain, J. J., Black, A. E., Davies, P. S. W., Steward, C. M., McKenna, P. G. \& Whitehead, R. G. (1992). Validation of estimates of energy intake by weighed dietary record and diet history in children and adolescents. American Journal of Clinical Nutrition 56, $29-35$. 
Livingstone, M. B. E., Prentice, A. M., Strain, J. J., Coward, W. A., Black, A. E., Barker, M. E., McKenna, P. G. \& Whitehead, R. G. (1990). Accuracy of weighed dietary records in studies of diet and health. British Medical Journal 300, 708-712.

Nelson, M., Black, A. E., Morris, J. A. \& Cole, T. J. (1989). Between- and within-subject variation in nutrient intake from infancy to old age: estimating the number of days required to rank dietary intakes with desired precision. American Journal of Clinical Nutrition 50, 155-167.

Paul, A. A. \& Southgate, D. A. T. (1978). McCance and Widdowson's The Composition of Foods, 4th ed. London: H.M. Stationery Office.

Southgate, D. A. T. (1986). Obese deceivers. British Medical Journal, 292, 1692-1693.

Tan, S. P., Wenlock, R. W. \& Buss, D. H. (1985). Immigrant Foods. Second Supplement to McCance and Widdowson's The Composition of Foods. London: H.M. Stationery Office.

Weir, J. B. de V. (1949). New method for calculating metabolic rate with special reference to protein metabolism. Journal of Physiology 109, 1-9. 